\title{
Wilms tumor with inferior vena cava duplication: a rare case report
}

\author{
Feng Guo ${ }^{1 \dagger}$, Tianyou Li ${ }^{1 \dagger}$, Wei Liu', Gang Wang ${ }^{1}$, Rui $\mathrm{Ma}^{2}$ and Rongde $\mathrm{Wu}^{1 *}$
}

\begin{abstract}
Background: Wilms tumor is the most common renal tumor of childhood. Duplication of the inferior vena cava is an uncommon anomaly. In the present study, we present a case of Wilms tumor with the inferior vena cava duplication, which has not been reported previously.

Case presentation: A 14-month-old female presented with an enlarging abdominal mass. Computed tomography imaging demonstrated a large mass in the right kidney, duplication of the inferior vena cava below the renal veins and compression of the right inferior vena cava caused by the enormous mass. A right radical nephrectomy was performed. Final pathology was consistent with Wilms tumor. Postoperative adjuvant chemotherapy was executed. Computed tomography imaging at 3 months postoperatively showed the right inferior vena cava played a dominant role and the left inferior vena cava was not detected clearly. During the follow-up of 18 months, no local recurrence or metastasis has been observed.
\end{abstract}

Conclusion: It is important to recognize the case of Wilms tumor with the inferior vena cava duplication to avoid injury of retroperitoneal venous anomalies and life-threatening hemorrhage during surgery through preoperative computed tomography.

Keywords: Wilms tumor, Inferior vena cava duplication, Computed tomography

\section{Background}

Wilms tumor (WT) is the most common renal tumor in childhood. Duplication of the inferior vena cava (IVC) is an uncommon anomaly. Although it is asymptomatic and often detected incidentally by imaging, IVC duplication may represent a hazard for bleeding during surgery, such as nephrectomy. In the present study, we present a case of WT with IVC duplication, which has not been reported previously.

\section{Case presentation}

A 14-month-old female was referred to our hospital with a history of an enlarging abdominal mass noted by her parents for 3 days. Physical examination revealed an abdominal mass with clear and smooth margins extending from the right upper quadrant to the right hemipelvis.

\footnotetext{
* Correspondence: wrd2190@126.com

${ }^{\dagger}$ Feng Guo and Tianyou Li contributed equally to this work.

'Department of Pediatric Surgery, Shandong Provincial Hospital Affiliated to Shandong University, 324 Jingwu Road, Jinan 250021, Shandong Province, People's Republic of China

Full list of author information is available at the end of the article
}

Routine blood tests were normal apart from mild anaemia and urine analysis did not show hematuria. Ultrasonography of the abdomen revealed a unilateral $10.8 \times 7.2 \times 9.2 \mathrm{~cm}$ solid tumor in the right kidney, whereas the contralateral kidney was normal. Computed tomography (CT) revealed a large lesion arising from the inferior aspect of the right kidney, occupying the right flank and extending across the midline. Enhanced CT detected duplication of IVC below the renal veins and compression and displacement of the right IVC caused by the enormous tumor (Fig. 1). An additional movie file shows this in more detail [see Additional file 1].

Neither intravascular extension nor invasion to adjacent organs and regional lymph nodes was detected by CT. Chest radiography was reported normal.

With the presumptive diagnosis of WT, a right-sided radical nephrectomy was performed. Final pathology was consistent with favorable histology, stromal-predominant (60\%) WT. The renal vessel and IVC were tumor free. The renal hilar and para-aortic lymph nodes were also free from tumor and the final pathological stage was Stage I. According to the regimen of the National Wilms' Tumor 


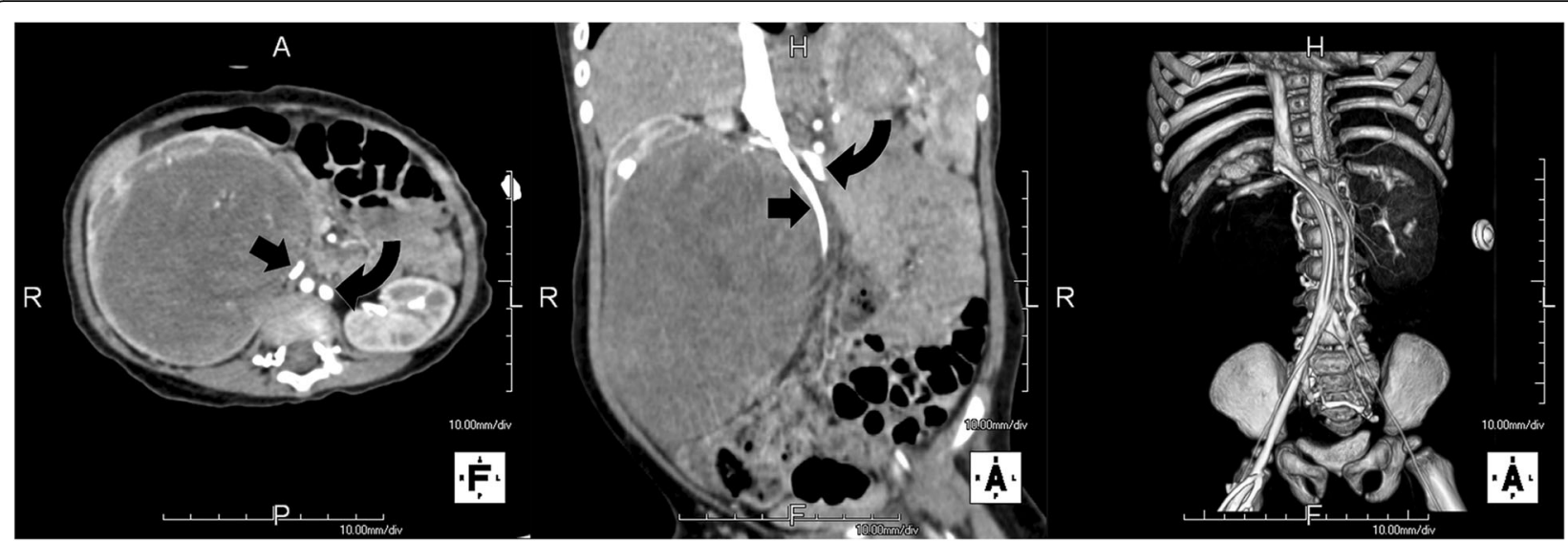

Fig. 1 Axial, coronal and three-dimensional reconstruction computed tomography scan with contrast showing a large mass in the right kidney, duplication of the inferior vena cava below the renal veins and compression and displacement of the right inferior vena cava. Straight arrow denotes the right inferior vena cava, and curved arrow the left inferior vena cava

Study Group 5, the patient received postoperative chemotherapy with dactinomycin and vincristine. CT imaging at 3 months postoperatively showed no evidence of residual or recurrent disease. Interestingly, the right IVC played a dominant role and the left IVC seemed to disappear in postoperative enhanced CT (Fig. 2). An additional movie file shows this in more detail [see Additional file 2]. During the follow-up of 18 months, no local recurrence or metastasis has been observed.

\section{Discussion}

WT is the most common tumor of the urinary tract under the age of 15 [1]. Up to now, WT with IVC duplication has not been reported. The development of the IVC is a complex embryological process between weeks 6 and 10 of gestation, including the development, regression, anastomoses, and replacement of embryonic veins [2]. Double IVC is a rare anomaly, and occurs in $1.5 \%$ (range $0.2-3 \%$ ) [3-5]. According to the caliber of the duplicated IVC and the preaortic trunk, IVC duplication has been classified into three types [4]. The classification may not be appropriate for the present case considering the notable changes of the caliber of the duplicated IVC before and after the operation. The compression of the right IVC caused by tumor resulted in the dominant venous drainage of the left IVC. After the tumornephrectomy, the right IVC gradually took over the venous drainage. Then the left IVC might start to regress and could not be detected at 3 months postoperative CT image. To our knowledge, this is the first detection of the postnatal regression of left IVC, which indicates that vena caval development might proceed not limited to the embryonic period.

Although IVC duplication is usually asymptomatic, it might have significant clinical implications. As an uncommon anomaly, the duplication of IVC can be misdiagnosed as a pathological lesion such as ureteric dilatation or lymphadenopathy on CT images. The left side of a double IVC might be interpreted erroneously as enlarged retroperitoneal lymph nodes $[2,6-8]$, which

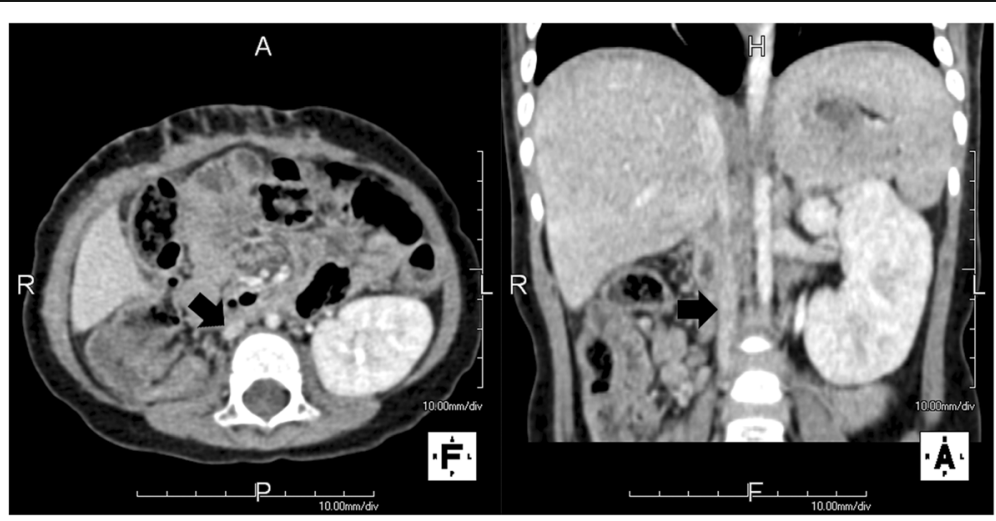

Fig. 2 Axial and coronal computed tomography scan with contrast 3 months after operation showing the right inferior vena cava played a dominant role and the left inferior vena cava was not detected clearly. Straight arrow denotes the right inferior vena cava 
might induce preoperative overstaging by radiographic imaging in WT. Serious overstaging due to erroneous interpretation of the CT appearance of a double IVC has been reported in testicular tumor $[6,7]$.

A radical nephrectomy with lymph node sampling is the "gold standard" surgical protocol for unilateral WT [9-11]. However, retroperitoneal surgery such as nephrectomy might injure the anomalous venous structures that are in fact typically thin walled, dilated and tortuous [12]. Thus, it is vital to recognize the abnormal vasculature such as IVC duplication and avoid a life-threatening hemorrhage in retroperitoneal surgery or intervention $[4,13-16]$.

In addition to an en bloc resection of the tumor, lymph node sampling is another significant goal in WT surgery [17]. However, patients with anomalous venous anatomy might have unusual patterns of lymph node metastases, for the reason that the lymphatic drainage generally follows the vascular architecture [18]. Thus, lymph node sampling or dissection in a patient with a venous anomaly might be adjusted accordingly [7].

WT involves IVC invasion in 4-8\% of cases [19], and caval extension of WT has been an important surgical challenge. Although tumor thrombus of renal vein or IVC was not found in the present case, extension of renal cell carcinoma into duplications of IVC and the retroaortic renal veins has been reported [18, 20-22].

$\mathrm{CT}$ is the most reliable technique for detecting tumor and retroperitoneal venous anomalies. Three-dimensional $\mathrm{CT}$ angiography can be used for detecting the duplication of IVC before surgery or other interventional procedures of the retroperitoneum are undertaken [23]. In WT, preoperative CT is also an important diagnostic tool and adjunct in assessing lymph node involvement to provide accurate treatment recommendations [24].

In our case, a plain chest X-ray was performed for the evaluation of pulmonary metastases and the report was normal. Considering the disadvantage of radiation exposure, a routine pulmonary CT that was still controversial [25] was not performed.

\section{Conclusion}

WT with IVC duplication is extremely rare. Preoperative $\mathrm{CT}$ can detect potential venous anomalies in retroperitoneum. Appropriate care can be taken to avoid injury of retroperitoneal venous anomalies and life-threatening hemorrhage during surgery.

\section{Additional files}

Additional file 1: Axial computed tomography sequential images with contrast before operation. (AVI $6664 \mathrm{~kb}$ )

Additional file 2: Axial computed tomography sequential images with contrast 3 months after operation. (AVI $5284 \mathrm{~kb}$ )
Abbreviations

$\mathrm{CT}$ : Computed tomography; IVC: Inferior vena cava; WT: Wilms tumor

Funding

This work was supported by grants from the National Natural Science Foundation of China(No.81501844), Shandong Provincial Natural Science Foundation(No.BS2015YY009) and Jinan Science \& Technology Development Program, China(No.201602170).

Availability of data and materials

Data sharing is not applicable as no data were generated and analyzed.

\section{Authors' contributions}

RW and FG made contributions to conception and design. FG and TL collected the patient details and wrote the paper. FG and WL made contributions to patient management. RM made contributions to computed tomography diagnosis and imaging. TL, GW and WL critically revised the article. All authors read and approved the final manuscript.

Ethics approval and consent to participate

The present study was approved by the Medical Ethics Committee of Provincial Hospital affiliated to Shandong University.

\section{Consent for publication}

Written informed consent was obtained from the parents of the patient for publication of this case report and any accompanying images. A copy of the consent form is available for review by the Editor of this journal.

\section{Competing interests}

The authors declare that they have no competing interests.

\section{Publisher's Note}

Springer Nature remains neutral with regard to jurisdictional claims in published maps and institutional affiliations.

\section{Author details}

${ }^{1}$ Department of Pediatric Surgery, Shandong Provincial Hospital Affiliated to Shandong University, 324 Jingwu Road, Jinan 250021, Shandong Province, People's Republic of China. ${ }^{2}$ Shandong Medical Imaging Research Institute, Medical School of Shandong University, Jinan, Shandong Province, People's Republic of China.

Received: 11 September 2017 Accepted: 4 October 2018

Published online: 19 October 2018

\section{References}

1. Birch JM, Breslow N. Epidemiologic features of Wilms tumor. Hematol Oncol Clin North Am. 1995;9(6):1157-78

2. Bass JE, Redwine MD, Kramer LA, Huynh PT, Harris JH Jr. Spectrum of congenital anomalies of the inferior vena cava: cross-sectional imaging findings. Radiographics. 2000;20(3):639-52.

3. Chen H, Emura S, Nagasaki S, Kubo KY. Double inferior vena cava with interiliac vein: a case report and literature review. Okajimas Folia Anat Jpn. 2012;88(4):147-51.

4. Natsis K, Apostolidis S, Noussios G, Papathanasiou E, Kyriazidou A, Vyzas V. Duplication of the inferior vena cava: anatomy, embryology and classification proposal. Anat Sci Int. 2010;85(1):56-60.

5. Jhansi P. Duplication of the inferior vena cava-report of a rare congenital variation. Int J Anat Var (IJAV). 2012;5:141-3.

6. Cohen SI, Hochsztein P, Cambio J, Sussett J. Duplicated inferior vena cava misinterpreted by computerized tomography as metastatic retroperitoneal testicular tumor. J Urol. 1982;128(2):389-91.

7. Klimberg I, Wajsman Z. Duplicated inferior vena cava simulating retroperitoneal lymphadenopathy in a patient with embryonal cell carcinoma of the testicle. J Urol. 1986:136(3):678-9.

8. Evans JC, Earis J, Curtis J. Thrombosed double inferior vena cava mimicking paraaortic lymphadenopathy. Br J Radiol. 2001;74(878):192-4

9. Ritchey ML, Kelalis PP, Breslow N, Etzioni R, Evans I, Haase GM, D'Angio GJ. Surgical complications after nephrectomy for Wilms' tumor. Surg Gynecol Obstet. 1992;175(6):507-14. 
10. Ritchey ML, Shamberger RC, Haase G, Horwitz J, Bergemann T, Breslow NE. Surgical complications after primary nephrectomy for Wilms' tumor: report from the National Wilms' tumor study group. J Am Coll Surg. 2001;192(1): 63-8 quiz 146

11. Fuchs J, Kienecker K, Furtwangler R, Warmann SW, Burger D, Thurhoff JW, Hager J, Graf N. Surgical aspects in the treatment of patients with unilateral wilms tumor: a report from the SIOP 93-01/German Society of Pediatric Oncology and Hematology. Ann Surg. 2009;249(4):666-71.

12. Downey RS, Sicard GA, Anderson CB. Major retroperitoneal venous anomalies: surgical considerations. Surgery. 1990;107(4):359-65.

13. Bartle EJ, Pearce WH, Sun JH, Rutherford RB. Infrarenal venous anomalies and aortic surgery: avoiding vascular injury. J Vasc Surg. 1987;6(6):590-3.

14. Karkos CD, Bruce IA, Thomson GJ, Lambert ME. Retroaortic left renal vein and its implications in abdominal aortic surgery. Ann Vasc Surg. 2001:15(6):703-8.

15. Christakis $P G$, Cimsit B, Kulkarni S. Complication arising from a duplicated inferior vena cava following laparoscopic living donor nephrectomy: a case report. Transplant Proc. 2012;44(5):1450-2.

16. Stefanczyk L, Majos M, Majos A, Polguj M. Duplication of the inferior vena cava and retroaortic left renal vein in a patient with large abdominal aortic aneurysm. Vasc Med. 2014;19(2):144-5.

17. Kieran K, Anderson JR, Dome JS, Ehrlich PF, Ritchey ML, Shamberger RC, Perlman EJ, Green DM, Davidoff AM. Lymph node involvement in Wilms tumor: results from National Wilms Tumor Studies 4 and 5. J Pediatr Surg. 2012;47(4):700-6.

18. Habuchi T, Okagaki T, Arai K, Miyakawa M. Renal cell carcinoma extending into left side of double inferior vena cava. Urology. 1993;41(2):181-4.

19. Khanna G, Rosen N, Anderson JR, Ehrlich PF, Dome JS, Gow KW, Perlman E, Barnhart D, Karolczuk K, Grundy P. Evaluation of diagnostic performance of $\mathrm{C}$ for detection of tumor thrombus in children with Wilms tumor: a report from the Children's oncology group. Pediatr Blood Cancer. 2012;58(4):551-5.

20. Handel DB, Heaston DK, Korobkin M, Silverman PM, Dunnick NR. Circumaortic left renal vein with tumor thrombus: CT diagnosis with angiographic and pathologic correlation. AJR Am J Roentgenol. 1983; 141(1):97-8.

21. Pinsk R, Nemcek AA Jr, Fitzgerald SW. Tumor thrombus in a retroaortic left renal vein and incidental right circumcaval ureter. Urol Radiol. 1992; 13(3):166-9.

22. Kumar S, Panigrahy B, Ravimohan SM, Pandya S, Mandal AK, Singh SK. Rare case of renal cell carcinoma with double inferior vena cava with venous thrombosis. Urology. 2008;72(2):461 e7-10.

23. Mathews R, Smith PA, Fishman EK, Marshall FF. Anomalies of the inferior vena cava and renal veins: embryologic and surgical considerations. Urology. 1999;53(5):873-80.

24. Lubahn JD, Cost NG, Kwon J, Powell JA, Yang M, Granberg CF, Wickiser JE, Rakheja D, Gargollo PC, Baker LA, et al. Correlation between preoperative staging computerized tomography and pathological findings after nodal sampling in children with Wilms tumor. J Urol. 2012:188(4 Suppl):1500-4.

25. Owens CM, Veys PA, Pritchard J, Levitt G, Imeson J, Dicks-Mireaux C. Role of chest computed tomography at diagnosis in the management of Wilms' tumor: a study by the United Kingdom Children's Cancer study group. J Clin Oncol. 2002:20(12):2768-73.

\section{Ready to submit your research? Choose BMC and benefit from:}

- fast, convenient online submission

- thorough peer review by experienced researchers in your field

- rapid publication on acceptance

- support for research data, including large and complex data types

- gold Open Access which fosters wider collaboration and increased citations

- maximum visibility for your research: over $100 \mathrm{M}$ website views per year

At $\mathrm{BMC}$, research is always in progress.

Learn more biomedcentral.com/submissions 